\title{
AIDS-Related Non-Hodgkin Lymphoma of the Cervix
}

National Cancer Institute

\section{Source}

National Cancer Institute. AIDS-Related Non-Hodgkin Lymphoma of the Cervix. NCI

Thesaurus. Code C7434.

A non-Hodgkin lymphoma that arises from the cervix in a patient with acquired immunodeficiency syndrome. 